\title{
A real-time dive on active hydrothermal vents
}

\author{
J. Sarrazin ${ }^{1}$, P.M. Sarradin ${ }^{1}$, E. Buffier ${ }^{2}$, A. Christophe ${ }^{3}$, G. Clodic $^{1}$, D. Desbruyères ${ }^{1}$, Y. Fouquet ${ }^{1}$, M. \\ Gouillou ${ }^{1}$, M. Jannez ${ }^{3}$, Y. Le Fur ${ }^{1}$, J. Le Rest ${ }^{1}$, F. Lecornu ${ }^{1}$, O. Lefort ${ }^{1}$, S. Lux ${ }^{2}$, B. Millet ${ }^{1}$, P. \\ Guillemet ${ }^{3}$.
}

\begin{abstract}
The Momareto cruise was held from August 6 to September 6, 2006 on the new French oceanographic vessel Pourquoi pas? The ROV Victor 6000 visited three vent fields, ranging from $850 \mathrm{~m}$ to $2300 \mathrm{~m}$, on the Mid-Atlantic Ridge. The scientific objective of the cruise was to study the spatial and temporal dynamics of hydrothermal communities colonizing these active vent sites. Aside scientific and technological objectives, one of the major goals of this cruise was to share the excitement of our science with the public. For this, the results of the project were shared through different media. The most challenging and exciting communication event remains the realtime transmission of images acquired by the ROV Victor at $1700 \mathrm{~m}$ depth to a 250 person audience on land.
\end{abstract}

Index Terms-Deep-sea, ecosystems, outreach, real-time

\section{INTRODUCTION}

$\mathrm{M}$ OST marine ecosystems rely on organic inputs derived from photosynthetic processes. Even in the deep ocean, the vast majority of the fauna depends upon surface material for its survival. Recently, peculiar ecosystems were discovered at thousand of meter depth along mid-ocean ridges. Hydrothermal vent ecosystems are sustained by an alternative pathway: chemosynthesis. Microbial organisms use the chemical energy from the hot fluids to synthesize organic matter, and form the base of the food chain. The environment around hydrothermal vents is extremely hostile. There is no light, the pressure is higher than what we experience on Earth, and the vent fluids contain toxic chemicals. Paradoxically, the vent hosts luxuriant faunal communities that thrive in this somewhat adverse habitat. Beside their insularity in the abyssal plain, vent ecosystems are characterized by high levels of natural perturbations, by the presence of a specific fauna (endemism) and by an important biological productivity. The remoteness and size of vent communities make them difficult

Manuscript received March 30, 2007.

The C-band VSAT antenna was funded through a Eureka Force 8 project, $\mathrm{n}^{\circ}$ 3194. Part of MoMARETO was funded by the EXOCET/D European project, contract \# GOCE-CT-2003-505342.

Corresponding author: Jozée Sarrazin, jozee.sarrazin@ifremer.fr

1. Ifremer, Centre de Brest, 29280 Plouzané, France

2. Ifremer, siège. Issy-Les-Moulineaux, Paris

3. Ifremer, Département SM, Centre de Toulon, 83507 La Seyne sur mer, France to access with conventional oceanographic instrumentations deployed from surface vessels. Their study rather requires the use of submersibles able to work on the seafloor.

Since their discovery, the study of hydrothermal vents, nicknamed "Oases at the bottom of the sea", has thrilled the imagination and animals surviving this extreme habitat, such as the giant tube worm Riftia pachyptila or the hairy galatheid crab Kiwa hirsuta, almost became heroes (Fig. 1). Hydrothermal ecosystems have all the ingredients needed to tease the public. They are located in the ocean at several meters depth, they harbour a strange exotic fauna, exhibiting strange morphological and physiological adaptations and they are visually astonishing. In addition, the up-to-date technology used for their study, including submersibles, is fascinating. During the preparation of the MoMARETO cruise proposal, it was clear to us that communication should be an integrated part of our objectives.

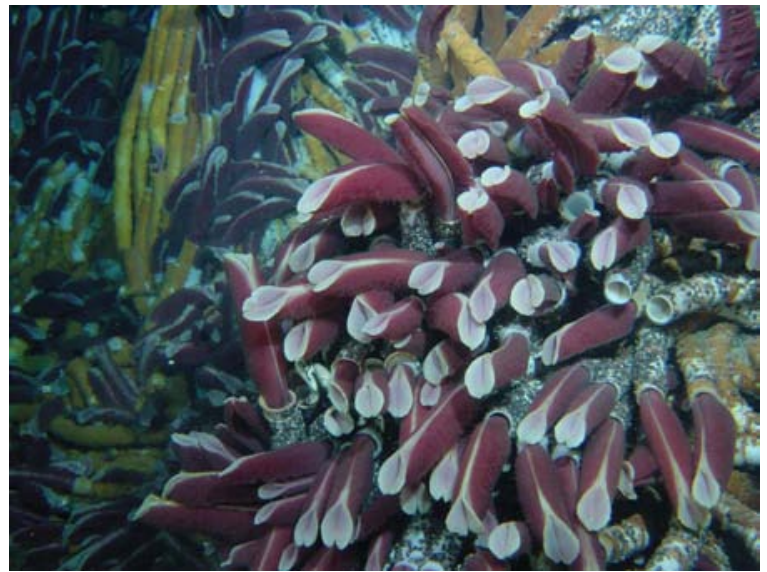

Fig.1. A bush of the giant Riftia pachyptila tube worms colonizing hydrothermal vents of the Pacific Ocean, Phare 2002 @Ifremer

MoMARETO was held from August 6 to September 6, 2006 on the new French oceanographic vessel Pourquoi pas? The scientific objective of the cruise was to study the spatial and temporal dynamics of hydrothermal communities colonizing the MoMAR zone, using innovative technologies (Sarrazin et al. 2006). The ROV Victor 6000 visited three vent fields, ranging from $850 \mathrm{~m}$ to $2300 \mathrm{~m}$, on the Mid-Atlantic Ridge (Fig. 2). Six dives were dedicated to the final integration and validation phase of prototypes developed during the European EXOCET/D project (Sarradin et al., this issue). A fine-scale bathymetric study of the Lucky Strike area, using a new survey module, was also conducted (Siméoni et al. this issue). During the second leg, 17 dives were spent to study the 
response of different hydrothermal species to their environment at two temporal scales: a very short-term response of organisms to habitat micro-variations (hours-days) and a longer observatory-type scale where the dynamics of faunal assemblages will be linked to broader-scale habitat variations (months-years).

Aside scientific and technological objectives, one of the major goals of this cruise was to share the excitement of our science with the public. For this, the results were shared through different media (web page, press papers, TV and radio shows). The most challenging and exciting communication event remains the real-time transmission of images acquired by the ROV Victor (Fig. 2) at $1700 \mathrm{~m}$ depth, giving live access to this fabulous ecosystem to a 250 person audience on land.

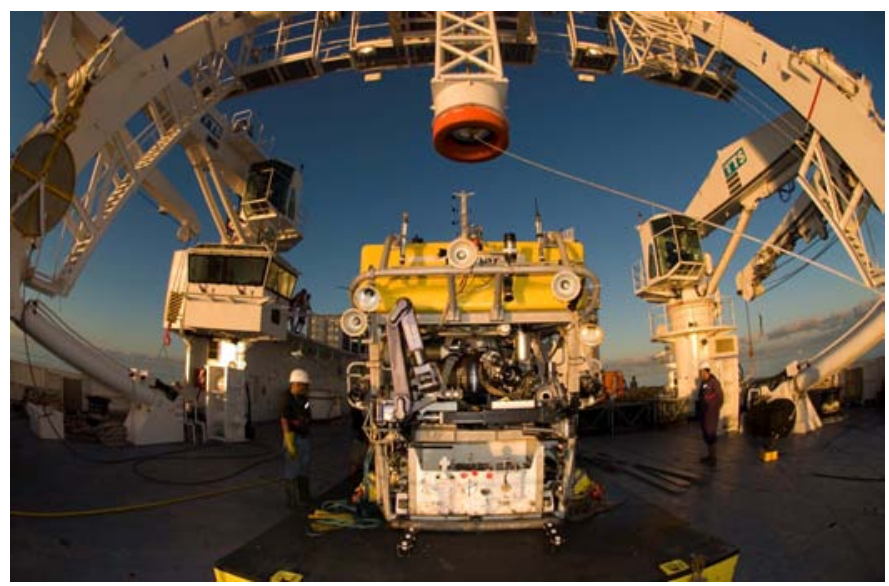

Fig. 2 The Remotely Operated Victor 6000, the star of the night !

\section{COMMUNiCATION STRATEGY}

A dedicated public outreach strategy was implemented during the MoMARETO cruise. This cruise represented a great opportunity:

- to discover oceanographic research on a state-of-theart research vessel,

- to accompany scientists, engineers and technicians in their day-to-day life at sea,

- to participate to the deployment of the latest, bizarre deep-sea instruments,

- to learn about the different jobs done at sea,

- to encounter a strange and unique fauna living near hydrothermal vents.

The promotion of our cruise started with a press conference in Paris in June 2006, followed by a press release two months before the cruise.

During the cruise, a day-to-day log book allowed close interactions with web users (www.ifremer.fr/momareto) (Fig. $3)$.

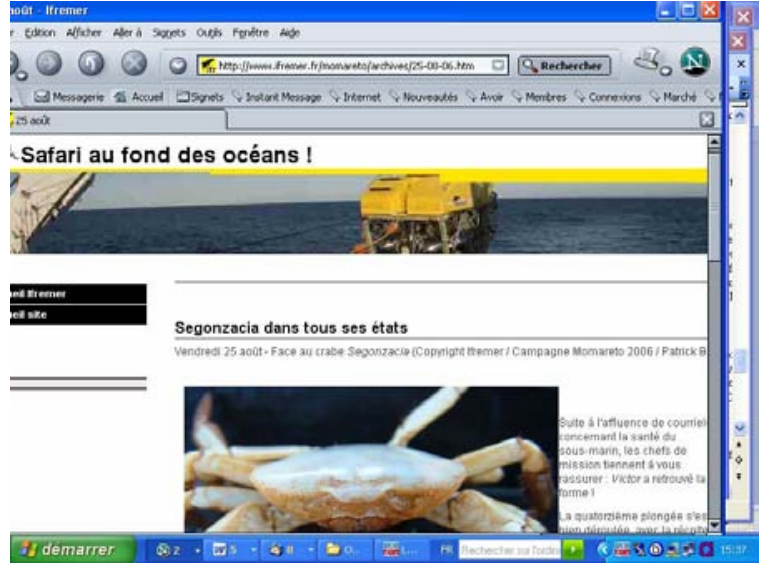

Fig. 3. Snap shot of the Momareto web site.

This interactive website included a short abstract of the dive, the weather, the menu, daily scoops, the area visited and the results. The ship operations and crew members were brought forward through dedicated texts (galley, machinery, pilots, ROV operators, deck crew ...). Small video clips (ca. 3 min) were periodically inserted in the web site. The objective was to present portraits, laboratory experiments and life on board. Focused pages presenting the instruments used or the fauna encountered were also available. A drawing contest for children was launched during the cruise with up to 20 participants ranging from 2 to 65 years old.

In 2006, the web site was visited by more than 12000 net surfers (outside Ifremer users) requested not less than 95000 web pages. The site remained visited in 2007 by approximately 2000 users per month. The content of the site was translated in Portuguese on board and presented within the IMAR/DOP internet site (http://www.horta.uac.pt/intradop/). Several other web sites referred to MoMARETO.

Cruise events were reported in several national and international newspapers, radio and TV shows. More than 25 journals talked about the research done during MoMARETO (Le Monde, L'Express, Libération, Le Figaro, Ouest France, Le Nouvel Observateur, Ushuaia magazine, etc.). Three of these papers were written by journalists invited on board for 24 hours, thanks to a shuttle with the Portuguese R/V Archipelagó. Ten radio shows (for ex. RFI, Europe 1, RadioCanada) and five TV shows (TF1, France 2, LCP, Finish TV) were also dedicated to the cruise, including a 9 minutes in the prestigious Thalassa magazine.

A short 22 minute film, retracing the cruise highlights was realised. It was used as a support for several post-cruise conferences dedicated to the general public. A total of 6 conferences for general public were done since the end of the cruise [Brest, Nantes, Rennes (France), Montréal, Sherbrooke (Canada)].

\section{A REAL TIME DIVE}

The idea of trying to reach the public directly was thrilling to us and the ship offered the new technology requested. So was 
born the "Nuit des Abysses": a real-time transmission of images from the ocean bottom to the public on shore.

\section{A. Technological requirements}

The first challenge encountered was a technological one. How can we transmit in real-time high-quality video images from the deep ocean to a conference room?

On the ship: A C-band VSAT satellite antenna has been installed on the top deck of the Pourquoi pas? offering up to 2 $\mathrm{Mb}$ bandwidth, 24 hours a day. This link allows internet access, transmission of phone calls, videoconferences and real time video. A dedicated real time information system already uses MPEG4 encoders to broadcast video streams on the vessel. The same technology was used to send real time high quality images taken by the ROV Victor to Brest.

On land: A video conference system, a dedicated video decoder and a projector were set in a conference room at the Ifremer Center in Brest. All was done to give the impression that the audience was "virtually" on the vessel bridge with the crew and scientists to participate to the dive.

The technical logistics involved was important. Only for the real-time transmission, 6 people on land and 3 people on board were involved.

\section{B. Scenario of the dive}

To prepare the event, a precise scenario of the dive was elaborated to make the most of the various landscapes observed in the area: lava lake, chaotic pillow lava, active hydrothermal edifice and of course, the particular fauna that colonize these chemosynthetic ecosystems. To insure that the show remained captivating and was synchronized with the land schedule, Victor $6000 \mathrm{ROV}$ was trained a few hours during three dives to follow a precise path on the perturbed seafloor. A back-up of the dive was also recorded and sent on land to prevent any communication failure or dive problems.

\section{Scenario of the event}

As for the dive, a precise scenario of the night was carefully established, considering the multiplicity of the audience (from children to seniors) and the two hours time lag between land and the ship. The schedule was particularly tight and coordination -en duplex- between the two remote sites was a real challenge.

\section{The event}

The event was planned on the 31 August 2006 at Ifremer, Brest Centre. Invitations were sent to 1000 persons, including the family of the cruise participants and of the crew members. The conference room, holding 250 persons, was packed. The night started by a welcome word by Jean-Yves Perrot, head of Ifremer. Then, three speakers presented the context of the cruise, the ship and ROV as well as the cruise objectives. This one hour introduction was followed by a videoconference between the scientists, crew and ROV team on board and, the public on shore to introduce the dive (Fig. 4). The ROV projectors were shut off. Progressively, the projectors were lighted on the chaotic ocean bottom. The public was left for 45 minutes with Victor live images from the deep ocean. Victor traveled through different landscapes. The submersible arm was deployed to measure temperature in the fluids of a spectacular black smoker. Close-up imagery of the fauna colonizing the edifice was also presented. Victor finished its itinerary at the top of Tour Eiffel, an $11 \mathrm{~m}$ high hydrothermal edifice, exhibiting a "the end" marker in its claw. A period of questions followed, allowing the public to directly interact with the people on board. Cruise scientists from different disciplines assisted to answer the questions.

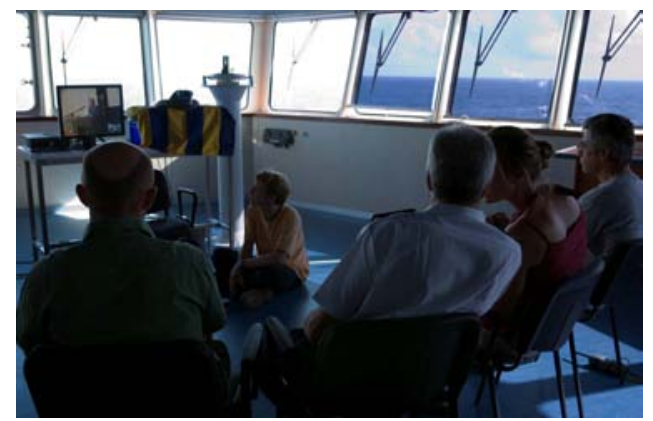

Fig. 4. The videoconference was set on the bridge of the research vessel Pourquoi pas? The captain, the chief ROV pilot and the two chief scientists were interacting with the public to introduce the dive.

The kids were thrilled and brought their intensity and emotions on board the Pourquoi pas? (Fig. 5). The most difficult question being asked by a three years old boy: "When are you coming home, dad?"

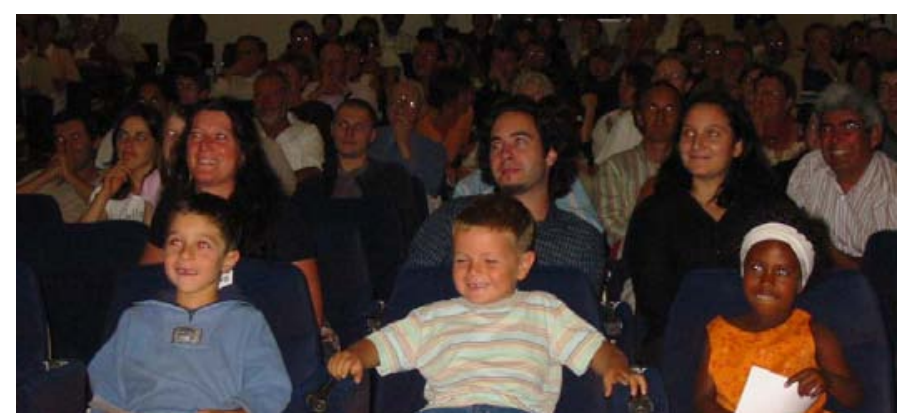

Fig. 5. The audience was concentrated during the whole event and particularly, during Victor dive at $1750 \mathrm{~m}$ depth.

\section{CONCLUSION}

The success of this communication plan relied on the facts that it was planned long in advance (as early as the cruise proposal done in 2004). Two berths were dedicated to Ifremer communication professionals during the cruise. Even though their role was important, especially for press contacts, the involvement of the scientists remained crucial to insure the success of the operation. For the "Nuit des abysses", it was important to have engineers and scientists on land to put the event in the context and to interact directly with the public.

On board, the communication plan developed had a strong 
effect on the crew and ROV pilots, whose hard work is often shadowed by the results of the on-going research. The web site, in particular, was a good way of recognizing the importance of each tasks and jobs to the realization and success of the cruise. This had a real positive impact on the ambiance and created a great synergy on board the ship.

The different communication actions reached not only a particular public but also different domains of the media. While the press conference and the web site attracted mostly written and radio media, only the real-time event gained the attention of the television. Interestingly, the event "Nuit des abysses" is cited directly in the Poseidon report, a report for policy makers to adopt a maritime strategy in France. The importance of pursuing fundamental deep-sea research is also highlighted in the report. Since research projects are funded by public money, it seems crucial that part of this work is given back to the public. Conversely, the more our research will be put forward, the better chance we have to be funded in the future.

\section{ACKNOWLEDGMENT}

We would like to thank the crew of the R/V Pourquoi pas? for their never-failing collaboration to the success of this cruise. We also acknowledge the Victor 6000 ROV team for their patience and constant support. We are grateful to all the Ifremer personal that was closely involved in the success of the MoMARETO communication plan, especially Marion Le Foll, Anne Faye, Alain Laponche and Danièle Lemercier. We are grateful to Jean-Yves Perrot that accepted to participate and support the event. The authors also express their sincere thanks to all the cruise participants for their good spirit and their will to share this unique experience. 